\title{
The Microbiome in Childhood Acute Lymphoblastic Leukemia
}

\author{
Marina Oldenburg ${ }^{1,+}$, Nadine Rüchel ${ }^{1,+}$, Stefan Janssen ${ }^{2} \mathbb{D}$, Arndt Borkhardt ${ }^{1}$ and Katharina L. Gössling ${ }^{1, * \mathbb{D}}$ \\ 1 Department of Pediatric Oncology, Hematology and Clinical Immunology, Medical Faculty, Center of Child \\ and Adolescent Health, Heinrich-Heine-University, 40225 Düsseldorf, Germany; \\ Marina.Oldenburg@med.uni-duesseldorf.de (M.O.); nadine.ruechel@med.uni-duesseldorf.de (N.R.); \\ Arndt.Borkhardt@med.uni-duesseldorf.de (A.B.) \\ 2 Algorithmic Bioinformatics, Department of Biology and Chemistry, Justus Liebig University Gießen, \\ 35390 Gießen, Germany; stefan.janssen@computational.bio.uni-giessen.de \\ * Correspondence: Katharina.Goessling@med.uni-duesseldorf.de \\ + These authors contributed equally to this work.
}

Citation: Oldenburg, M.; Rüchel, N.; Janssen, S.; Borkhardt, A.; Gössling, K.L. The Microbiome in Childhood Acute Lymphoblastic Leukemia. Cancers 2021, 13, 4947. https:/ / doi.org/10.3390/cancers13194947

Academic Editor: Csongor Kiss

Received: 29 July 2021

Accepted: 28 September 2021

Published: 30 September 2021

Publisher's Note: MDPI stays neutral with regard to jurisdictional claims in published maps and institutional affiliations.

Copyright: (c) 2021 by the authors. Licensee MDPI, Basel, Switzerland. This article is an open access article distributed under the terms and conditions of the Creative Commons Attribution (CC BY) license (https:/ / creativecommons.org/licenses/by/ $4.0 /)$.
Simple Summary: The role of the microbiome for the development and treatment of acute lymphoblastic leukemia (ALL) is not well understood. The immune system and microbiota closely interact and perturbations have strong implications for ALL development and course of the treatment. Significant differences in the microbiome with reduced diversity have been observed already at the onset of disease and have potential implications for leukemogenesis. Furthermore, the regular chemotherapeutic treatment regimen severely perturbs the microbiome, being associated with severe side effects such as mucositis, systemic inflammation, or infections. Herein, we review the latest microbiome studies in pediatric ALL patients, as well as provide an overview of current and future options to modulate the microbiome to improve the treatment's outcome or even prevent leukemia development.

Abstract: For almost 30 years, the term "holobiont" has referred to an ecological unit where a host (e.g., human) and all species living in or around it are considered together. The concept highlights the complex interactions between the host and the other species, which, if disturbed may lead to disease and premature aging. Specifically, the impact of microbiome alterations on the etiology of acute lymphoblastic leukemia (ALL) in children is not fully understood, but has been the focus of much research in recent years. In ALL patients, significant reductions in microbiome diversity are already observable at disease onset. It remains unclear whether such alterations at diagnosis are etiologically linked with leukemogenesis or simply due to immunological alteration preceding ALL onset. Regardless, all chemotherapeutic treatment regimens severely affect the microbiome, accompanied by severe side effects, including mucositis, systemic inflammation, and infection. In particular, dominance of Enterococcaceae is predictive of infections during chemotherapy. Long-term dysbiosis, like depletion of Faecalibacterium, has been observed in ALL survivors. Modulation of the microbiome (e.g., by fecal microbiota transplant, probiotics, or prebiotics) is currently being researched for potential protective effects. Herein, we review the latest microbiome studies in pediatric ALL patients.

Keywords: ALL; oral microbiome; fecal microbiome; microbiota; leukemogenesis; infection-triggered leukemia; childhood leukemia; induction therapy; consolidation therapy; maintenance therapy

\section{Current Status of Microbiome Analysis in Pediatric ALL}

Acute lymphoblastic leukemia (ALL) is the most frequent type of pediatric cancer [1], with an incidence rate of 5.4 per 100,000 cases in patients below the age of 15 years in 2017. Incidence peaks at 2-5 years of age [1]. Three major factors increase the risk of ALL development: exposure to radiation, previous cancer treatment, and genetic disorders. A distinction is made between B- and T-cell ALL cell lineages. The most common form is 
B-cell lymphoblastic leukemia, which involves several genetic disorders, such as ETV6RUNX1, BCR-ABL1, or hyperdiploidy [1]. In the last decade, microbial disbalance has been shown to influence the development of several immune diseases, including systemic lupus erythematosus, rheumatoid arthritis, and systemic sclerosis [2-4]. It has also been associated with oncogenesis and cancer progression in, for instance, the breast, pancreas, and white blood cells $[4,5]$. The influence of the microbiome on cancer development has been studied since 2012 [6], and investigations into adult ALL started two years later [7]. Although microbial disbalances have a substantial impact on several immune diseases, in cancer, it is remarkable that no relevant studies into childhood ALL were published until 2016 [8]. This might be attributed to the fact that microbiome analyses are susceptible to various problems, such as contaminations during preparation via buffers or handling, or poor processing choices due to high sequencing costs. Over the last decade, advances in technology and reductions in cost have increased microbial research interest and therefore the number of microbiome studies in leukemia [9]. Mouse experiments in the preclinical mouse model of Pax5/- and Sca1-ETV6-Runx1 mice already point to genetic predispositions altering the gut microbiome [10]. Before the onset of disease the mouse microbiome had been different between the different mouse genotypes [10]. This may further affect leukemia development and might even be used as a diagnostic tool in the future. Furthermore, based on epidemiological data, the current hypothesis of infection-triggered leukemia of the most common ALL subtypes (ETV6-RUNX1 and high-hyperdiploid chromosomes) during early childhood implies that a lack of microbial exposure in infancy can promote the emergence of this disease [11]. In 2018, stool samples of 42 pediatric patients at different timepoints of therapy were analyzed [12]. The comparison of acute myeloid leukemia (AML), ALL, and bone marrow transplant patients revealed a cancer-distinct microbiome. Specifically, a study in 2020 revealed the human microbiome as a diagnostic tool for specific cancer types [13].

Microbial composition is well adjusted to the specific conditions in different areas of the human body, depending on age, environmental lifestyle, antibiotic therapy, and diet. The symbiotic interplay between host and bacteria results in a healthy mucosa, which offers protection from overt pathogens and provides nutrients, such as short fatty acids and branched-chain amino acids, as well as the production of glycans and lactic acids (Table 1) [14-20]. Furthermore, the microbiome shapes and influences the immune system in a positive way by inducing innate and adaptive immune responses [4]. Studies have further revealed a profound impact on the early development of the innate immune system, referred to as trained immunity [15].

Table 1. Bacterial influence on nutrition and immunity.

\begin{tabular}{|c|c|c|c|c|c|}
\hline Phylum & Genera & Species & Nutrient & Immunity & Refs. \\
\hline Fusobacteria & & F. nucleatum & & NK & [21] \\
\hline \multirow[t]{6}{*}{ Firmicutes } & Clostridium & Cluster XIVa/IV & butyrate & Treg & [22] \\
\hline & Eubacterium & & lactic acid & & [19] \\
\hline & Faecalibacterium & F. prausnitzii & butyrate & TH17/Treg & [23] \\
\hline & Roseburia & & SCFAs & Treg & [17] \\
\hline & Ruminococcus & & butyrate & Treg & [22] \\
\hline & Enterococcus & & lactic acid & & [18] \\
\hline \multirow[t]{2}{*}{ Bacterioidetes } & Bacteroides & & glycans & & [20] \\
\hline & Prevotella & & & carbohydrates & [16] \\
\hline Actinobacteria & Bifidobacterium & & SCFAs & & [16] \\
\hline \multirow[t]{2}{*}{ Proteobacteria } & Helicobacter & & & TH1 & [24] \\
\hline & Escherischia & & & $\begin{array}{c}\text { protective against Salmonella } \\
\text { typhimurium and } \\
\text { Pseudomonas aeruginosa }\end{array}$ & {$[25,26]$} \\
\hline
\end{tabular}


The uptake of different bacteria in early childhood, by breast feeding, for example [27], is crucial for the development of a healthy immune defense, which decreases susceptibility to various infectious pathogens and autoimmune diseases [4]. Additionally, specific commensal bacteria directly affect immune cells; for example, Fusobacterium nucleatum interacts with natural killer cells (NK cells) to inhibit cytotoxicity, (Table 1) [21]. Helicobacter infection leads to inflammation, T cell infiltration and apoptosis [24]. Streptomyces carpaticus isolated of stool samples from healthy children was incubated with cancer cells in vitro and had a killing effect on malignant cells derived from a chronic lymphocytic leukemia patient [28]. Furthermore, intra-tumor injection of Streptomyces carpaticus in mice also prevents cancer cells infiltration of the light tight and so far, metastasis [28].

Interestingly, patients with acute myeloid leukemia and higher baseline levels of Porphyromonadaceae have been shown to be protected against infections [29], and the clinical outcome of allogeneic hematopoietic stem cell transplantation can be predicted by specific enteric biomarkers [30]. In contrast, no specific oral or gut microbiota has yet been identified as playing a role in ALL.

\section{Microbiome in ALL}

\subsection{Microbiome at Time of Diagnosis}

Several studies investigated the microbiome disbalance during and after the onset of ALL (Table 2). While the symbiotic interaction between microbiome and host might become important as a future diagnostic tool, it may also lead to therapy strategies that increase medical treatment success and prevent side effects. Knowing that the microbiota composition prevents pathogen colonization, interacts with the immune system, and enhances barrier function against bacterial blood stream contamination [4], it is important to understand how an increase or decrease in bacteria affects treatment strategy (Figure 1).

Table 2. Microbiome studies in pediatric ALL patients.

\begin{tabular}{|c|c|c|c|c|c|c|}
\hline Time Point & Sample Type & Patients & Controls & Time Points & Seq. Region & Refs. \\
\hline \multirow{4}{*}{$\begin{array}{l}\text { At time of } \\
\text { diagnosis }\end{array}$} & Oral & 13 & 13 & 1 & V1-V3 & [31] \\
\hline & Stool & $23+5$ & 23 & 4 & V1-V3 & [8] \\
\hline & Fecal & 30 & 33 & 1 & V3-V4 & [32] \\
\hline & Stool & 58 & 23 & 1 & V1-V9 & [33] \\
\hline \multirow{5}{*}{ During therapy } & Stool & 36 & 36 & $\begin{array}{l}\text { patients }=3 \\
\text { controls }=1\end{array}$ & $\mathrm{~N} / \mathrm{A}$ & [34] \\
\hline & Stool & 199 & 0 & 4 & V1-V3 & [35] \\
\hline & Stool & 32 & 25 & 13 & V4 & [36] \\
\hline & Anal swabs & 7 & 7 & 3 & $\mathrm{~V} 4$ & [37] \\
\hline & Stool & 51 & 19 & $\begin{array}{l}\text { patients }=5 \\
\text { controls }=2\end{array}$ & V3-V4 & [38] \\
\hline \multirow{5}{*}{$\begin{array}{l}\text { Complications } \\
\text { during therapy }\end{array}$} & Stool & 42 (15 ALL) & 0 & 1 & V3-V4 & [12] \\
\hline & Stool & 199 & 0 & 4 & V1-V3 & [35] \\
\hline & Stool & 16 & 0 & 2 & V4-V5 & [39] \\
\hline & Stool & 51 & 19 & $\begin{array}{l}\text { patients }=5 ; \\
\text { controls }=2\end{array}$ & V3-V4 & [38] \\
\hline & Oral & 39 & 39 & 1 & V1-V3 & [40] \\
\hline \multirow{4}{*}{ After therapy } & Anal swabs & 73 & 61 & 1 & V4 & [41] \\
\hline & Stool & 32 & 25 & 13 & $\mathrm{~V} 4$ & [36] \\
\hline & Stool & 38 & 16 & 1 & V4 & [42] \\
\hline & Anal swabs & 7 & 7 & 3 & V4 & [37] \\
\hline
\end{tabular}




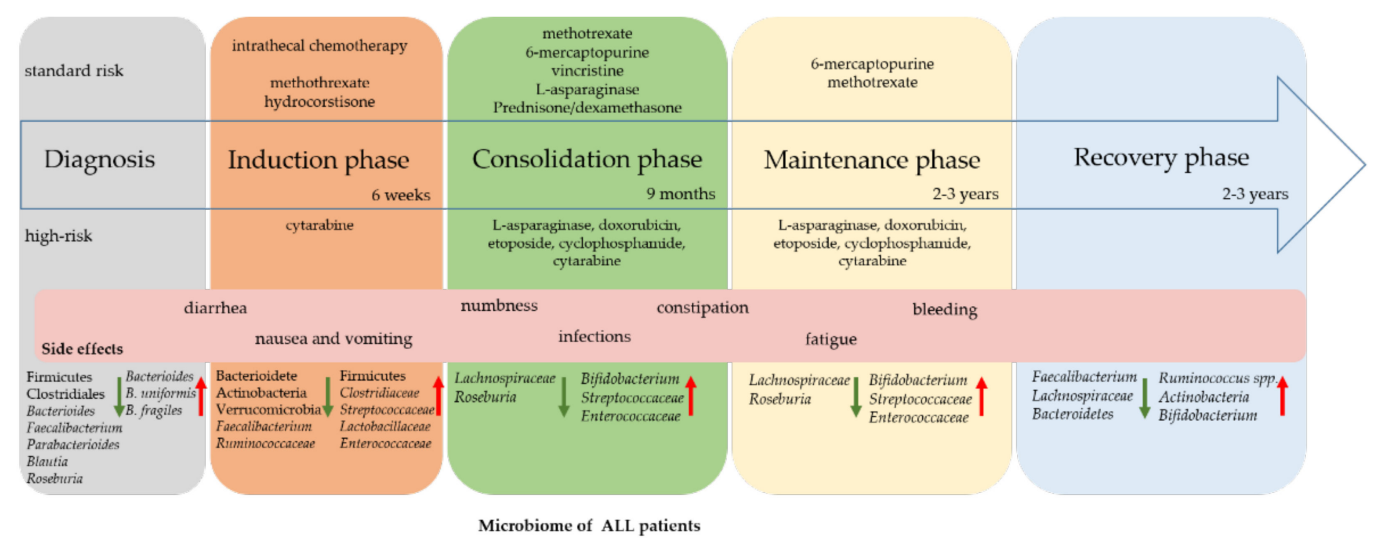

Figure 1. Microbial shift and side effects during therapy. During cancer therapy microbial composition shifts depending on medical treatment. Up (red arrow) and downregulated (green arrow) bacteria are listed from time-point of diagnosis, induction, consolidation, maintenance, and recovery phase. Side effects occur between all phases and cannot be assigned to a specific time. Therapy is divided into standard and high-risk with differences in therapeutical treatment.

Marker genes or whole DNA content of the many bacterial, viral, fungal, and archaeal species that make up a single microbiome are nowadays routinely sequenced via short read platforms like Illumina or in growing numbers with long read platforms like Pacbio or Oxford Nanopore. Alpha diversity is a measure for the complexity of a community in a single sample and is quantified, e.g., by the sheer number of different bacterial "species". The term species is a taxonomic rank, which remains to be assigned to the sequencing data and we should better use the terms "Operational Taxonomic Unit" (OTU), "Amplicon Sequencing Variant" (ASV) or "feature" instead of "species" in this context. Other alpha diversity metrics assess heterogeneity (Shannon index) or additionally consider evolutionary relationships between features (Faith's Phylogenetic Diversity). To express differences between two microbial communities, various metrics of beta diversity have been developed, e.g., Jaccard, which quantifies the number of shared features between two samples, or Bray Curtis, which is bases on Jaccard but weighs features with their relative abundance in both samples. Similar to Faith's PD, UniFrac incorporates distances. Much cheaper short read platforms limit sequencing to only parts of the full 16S rRNA marker gene. Popular choices are V1-V2, V3-4, or V6, but all come with significant biases in phylogenetic resolution, i.e., different species have the same sequence, and render meta analyses across different studies almost impossible (Table 2).

Comparing human stool samples with different $16 \mathrm{~S}$ regions as targets showed regionspecific differences, indicating poorly classified sequences in phyla or at the genus level [43]. Keeping that in mind, microbial analysis at the time of leukemia diagnosis is rare but necessary to identify bacteria that support leukemia development early diagnosis and prophylactic strategies to improve health status during chemotherapy.

\subsubsection{Oral Microbiome}

The microbiome harbored in the oral cavity is the second largest and second most diverse in the body. Disbalance might result in leukemic manifestations like paleness of oral mucosa, discoloration of gums, gingival petechiae, ulcerative necrotic lesions [44], or mucosal ulcers [45]. Impairment of the mucosa as the first natural protective barrier leads to subsequent diseases. Knowing the impact of ALL on the oral cavity at diagnosis and during chemotherapy, it is astonishing that only one study has investigated the microbiota at time point of diagnosis [31].

In some cases, patients suffer from tooth and jaw pain, gingival swelling and loose teeth, all of which might be influenced by a disturbed microbiome [31]. Oral samples from 13 newly diagnosed ALL patients and 12 healthy control children were collected $2 \mathrm{~h}$ after breakfast [31]. Of the 12 identified phyla, Proteobacteria, Firmicutes, Fusobacteria, Actinobacteria, and Bacteroidetes were the most prominent in both patients and healthy 
children. Comparing ALL patients and healthy controls, Firmicutes and Fusobacteria were significantly different. ALL patients had an increased abundancy of Firmicutes, while Fusobacteria abundance was decreased. Granulicatella and Veillonella, both belonging to Firmicutes, were more abundant in ALL patients [31]. Taken together, ALL patient samples displayed a reduced microbial diversity and lower richness, indicating a disbalance that might increase infection risks.

Notably, the above study differed from others in its sample collection methods, since researchers extracted supragingival plaque from teeth instead of the cheek or tongue mucosa, so further investigation focusing on the oral microbiome is required.

\subsubsection{Gut Microbiome}

Additional studies have been published focusing on the gastrointestinal microbiome as a potential factor in long-term effects after therapy (Table 2). Stool samples of acute B-cell leukemia and matched healthy controls show an increased abundance of Faecalibacterium, Bacterioides, or Parabacterioides, but a significantly reduced alpha diversity in patient samples [8,32]. In control groups, taxa such as Roseburia [8,33] and Firmicutes [32] show higher abundance instead. Interestingly, diarrhea-causing Clostridiales are less abundant in ALL children, as are Lachnospiraceae, whose members, including Roseburia and Blautia, produce short-chain fatty acids with an anti-inflammatory benefit (Figure 1) [8,32,46].

During the initial manifestation of the disease, some ALL patients receive antibiotic treatment because of their increased susceptibility to infection. Administration of antibiotics temporarily perturbs microflora, sometimes even permanently. Microbiota diversity significantly decreases in ALL patients treated with antibiotics in the one-month period prior diagnosis $[8,32]$. Comparing the microbiome composition of ALL patients treated with short- and long-term medication prior to chemotherapy identified a further change in alpha diversity, with a decreased number of specific bacteria like Firmicutes and Bacteroidetes [8,32]. In ALL patients, representatives of Firmicutes were fewer and Bacteroidetes increased abundantly [32]. This ratio was also seen in antibiotic-treated ALL patients compared to untreated patients, which means the antibiotic treatment has less effect on Firmicutes/Bacteroidetes ratio in ALL patients [32]. Based on these results, Bai et al. considered Bacteriodales and Enterococcaceae to be representative of the phylum Firmicutes as a possible biomarker for ALL, but only in children without antibiotic treatment [32].

In 2020, the largest cohort to date, 70 newly diagnosed ALL patients, was recruited at time of diagnosis [33]. Ultimately, stool samples of 60 patients with ALL and 23 healthy children were analyzed, after excluding those treated with antibiotic or probiotic supplements. While there was no difference in the alpha diversity, this study also verified increased Bacterioides species in the beta diversity. Specifically, Bacterioides uniformis and Bacteroides fragiles were significantly increased in pre-chemotherapy ALL patient samples [41]. Variations in the alpha and beta diversity may be caused by analyzing different regions of the $16 \mathrm{~S}$ rRNA. In the first studies, V1-V3 regions were amplified, while Bai et al. went further into the V3-V4 hypervariable regions, V1-V9, and latter V4 region (Table 2) [8,31-33].

\subsection{Changes during Therapy}

Early symptoms of childhood ALL, such as anemia-derived fatigue, fever, infection, and even easy bleeding, are often a result of the reduced number of blood cells. Therapy starts directly after diagnosis, with chemotherapy given in 3 phases over 2-3 years (Figure 1). Chemotherapy leads to a shift in bacterial composition and a decrease of the white blood cell counts; together this often leads to infection induced by bacteria. In a study with 409 newly diagnosed ALL patients, 1313 microbiologically derived infections were documented during therapy [47], and it was hypothesized that intestinal microbial changes caused infectious side effects. Although the damage done to the microbiome by chemotherapy has long been known, systematic investigation of altered microbial composition in ALL patients only started in 2016. Stool samples were collected from 28 newly diagnosed ALL patients at different points of treatment and from 23 controls [8]. Comparing the micro- 
biome before and after treatment, the diversity of composition was significantly reduced, with a specific reduction of Lachnospiraceae and Roseburia in patient samples. A larger study from Hakim et al. investigating the different time points analyzed 199 ALL patient stool samples at three different points during chemotherapy [35]. Interestingly, comparing the different time points with each other, no significant difference was found in the mean diversity, and furthermore it "recovered" to baseline, but the microbial diversity significantly decreased after chemotherapy, with a different bacterial composition (Figure 2).

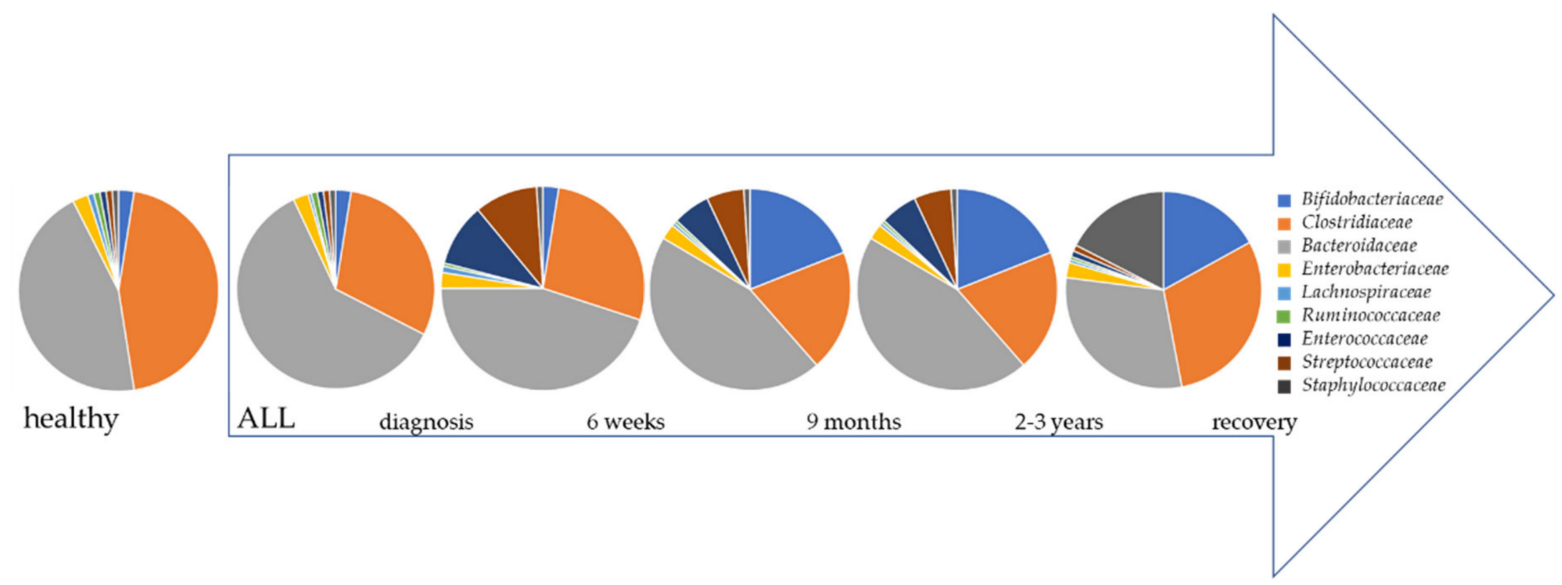

Figure 2. Microbial composition shifts during therapy phases. At timepoint of diagnosis composition already differs from ALL patients compared to healthy children. Clostridiaceae and Bacteroidaceae are predominant species in healthy children [31,48]. At time of diagnosis Bacteroidaceae abundance prevails in ALL patients while Clostridiaceae and Lachnospiraceae decrease [31]. During the first 6 weeks of therapy namely induction phase, Ruminococcacea decrease, unlike Streptococcaceae and Enterococcaceae, whose abundances increase $[35,36,38]$. While bacterial load decreases in general within consolidation ( 9 months) and maintenance phase (2-3 years) the abundance of Lachnospiraceae and Clostridiceae decreases drastically, whereas spectrum of Bifidobacteriaceae, Streptococcacea, and Enterococcaceae emerged [35]. At the end of therapy microbial composition significantly differs from healthy children. ALL children still show an increase of Bifidobacteriaceae and Staphylococcaceae, and a decrease of Clostridiaceae and Bacteroidaceae [41]. This figure is a schematic representation and displays trends, not exact numbers.

During therapy, Bacterioidetes, Faecalibacterium, Ruminococcaceae, Actinobacteria, and Verrucomicrobia significantly decreased, while other taxa, Clostridiaceae, Streptococcaceae, Lactobacillaceae, Enterococcaceae, and Firmicutes, increased [35]. Two more studies have underlined the reduced microbial diversity related to chemotherapy treatment, analyzing in each case 32 and 51 newly diagnosed ALL patients with 13 different time points within a year and 5 time points within a month, respectively $[36,38]$.

It seems that beta diversity of the family Ruminococcaceae decreased [35], but specific species (e.g., Ruminococcus gnavus and Ruminococcus torques) tended to increase as a result of chemotherapy and were elevated after a year [36]. However, not only was the beta diversity diminished, but the alpha diversity in patient samples was also reduced within one month after chemotherapy, and then increased on day 29 [38].

Five years later, based on their initial study, Rajagopala et al. focused on prophylactic antibiotic treatments during therapy to prevent side effects [36]. Likewise, De Pietri et al. directly pointed out the interplay between bacterial species and specific proteins of systemic inflammation and enterocyte loss [38].

The first examination of temporal changes in the gut microbiome was conducted via a longitudinal observation study, with samples collected from seven ALL patients before, during and after chemotherapy and from controls [41]. Antibiotic treatment before chemotherapy made no difference that might explain the observed large inter-individual variability in ALL patients compared to healthy children. Nevertheless, Bacteroidetes was significantly enriched before chemotherapy and although its abundance decreased after 
therapy, it was still higher than in control samples [41]. Abundance of Firmicutes and Actinobacteria, on the other hand, increased following chemotherapy to a level similar to that of healthy controls. Five genera stood out with a lower abundance after therapy: Bacteroides and Prevotella, belonging to the phylum Bacteroidetes; Fusobacterium; and Atopobium and Corynebacterium from Fusobacteria and Actinobacteria, respectively. Interestingly, only Bifidobacterium (Actinobacteria) was significantly higher in the post-chemotherapy samples. This commensal occurs immediately following birth [49] and was described to be able to use human milk oligosaccharides, as well as other carbon sources [50]. Furthermore, it has a protective role in preventing intestinal inflammation in infants since it prevents an increase of Proteobacteria which are associated with dysbiosis and negative health outcomes [50].

\subsection{Complications, Infections}

Antibiotic treatment and chemotherapy have detrimental effects on microbial composition. Febrile neutropenia, diarrheal, and therefore systemic inflammation and enterocyte loss often occur during therapy [35,38]. For instance, pathogenic bacterial overgrowth negatively affects the mucosa and thus the associated immune system $[51,52]$. Bloodstream infections occur due to an ineffective natural barrier against the invading microorganisms [52], indicating that a healthy microbiome not only provides nutrition and a natural barrier, but it also influences the outcome of medical treatment.

Firmicutes and Bacteroidetes are the prominent phyla in the gut microbiome. The ratio between Firmicutes (decrease) and Bacteroidetes (increase) has been introduced as an indicator of a dysregulated microbiome [32]. The Firmicutes and Bacteroidetes change in ALL patients is independent of antibiotic treatment, but it leads to a dysregulation in healthy controls [32]. For example, Megamonas, a species which belongs to the phylum Firmicutes and is correlated with inflammation, is more abundant in antibiotic-treated ALL patients [32,53].

During chemotherapy, patients suffer from bloodstream infection, diarrheal illness, or febrile neutropenia and can also develop oral diseases. In a cohort of 39 ALL-diagnosed and 39 healthy children, only ALL patients developed oral mucositis and candidiasis (15.4\% and 2.6\%, respectively) [40]. Lactobacillales belonging to the phylum Firmicutes were more abundant in ALL patients. The increase in Lactobacillus strains [40] is associated with reduced wound-healing capacity [54]. Dental cavities and gingivitis also occurred more frequently in ALL patients (69.4\% vs. 38.5\%) [40].

In a cohort of 199 treated children diagnosed with ALL, 13\% suffered a bloodstream infection, $61 \%$ a febrile neutropenia and 37\% a diarrheal illness [35]. Enterococcus, Staphylococcus and Enterobacter were found in the bloodstream, corresponding to an increase in Enterococcaceae or Streptococcaceae during therapy [35]. The increase in Streptococcaceae was also associated with diarrheal illness and Enterococcaceae with developing febrile neutropenia. Investigation in a rat model showed that diarrhea was accompanied by a decreased presence of commensal protective anaerobic species like Ruminococci and oxygen-tolerant Streptococci [55]. This trend is also seen in ALL patients, but the impact of single therapeutics on the microbiome is less investigated in humans. One such compound is methotrexate, a chemotherapeutic drug commonly used in the treatment of ALL (Figure 2) [56]. Its influences on the microbiome have been investigated in mouse and rat models, as well as in ALL-diagnosed children [34,55,57]. After high-dose methotrexate therapy in ALL patients, Bifidobacteria, Lactobacillus, and Escherischia coli (E. coli) abundancy decreased [34]. E. coli protects mice from intestinal inflammation caused by Salmonella typhimurium infection [25]. Furthermore, it was described to prevent intestinal colonization by Pseudomonas aeruginosa [52]. Lactobacillus was described to reduce inflammation by regulation of regulatory $\mathrm{T}$ cells, which secrete the anti-inflammatory cytokine IL-10 [58]. Surface-associated molecules from Bifidobacteria act by activating pattern recognition receptors (PRRs) on immune cells to elicit an immunomodulatory response [59]. In a mouse model, mucosal damage was accompanied by inflammatory cell infiltration, as well as gradually reduced diversity [57]. 
Comparable with human studies, Bacteroidetes abundancy was reduced while, contrary to ALL patients during therapy, Lachnospiraceae was increased [57]. During the consolidation phase, patients are commonly treated with corticosteroids (e.g., prednisone or dexamethasone) in addition to methotrexate (Figure 1), which are known to affect the microbiome directly. For instance, dexamethasone application leads to an increase in Bifidobacterium and Lactobacilli, and a decrease in Mucispirillum, while treatment with prednisone has an increasing effect on the abundance of Streptococci and Bifidobacteria [60]. An increase in Faecalibacterium occurs with enhanced occludin and E-cadherin expression [60]. Intestinal microbiota also interfere with treatment by degrading corticosteroids into inactive compounds. Clostridium scindens has been shown to metabolize prednisone in a mouse model [61], but this effect has not yet been investigated in ALL patients. The cytostatic drug 6-mercaptopurine is metabolized to 6-thioguanine, which leads to cell cycle arrest and apoptosis [62]. Interestingly, it has been shown that E. coli also metabolizes 6-mercaptopurine to active thioguanine nucleotides without host enzymatic reaction [60]. Bacteroides fragilis and Enterococcus faecalis provide enzymes that are necessary for conversion into an active compound, such as hypoxanthine-guanine phosphoribosyl transferase (HGPRT) or guanosine monophosphate synthetase (GMPS) [60,63], indicating the importance of microbial composition. Additional studies are available for high-risk therapeutics like doxorubicin, etoposide, and cyclophosphamide. In a mouse model, administration of doxorubicin increased epithelial barrier permeability, which led to bacterial translocation and, consequently, mucosal damage [64]. In the colon, Raoultella planticola, a member of the Enterobacteriaceae family, inactivates doxorubicin via an anaerobic-dependent deglycosylation pathway [65]. Cyclophosphamide treatment leads to increased intestinal permeability and, as a consequence, to bacterial translocation [66]. Additionally, the predominance of potentially pathogenic species belonging to Enterobacteriaceae, Enterococcaceae, and Pseudomonaceae can occur [67]. Viaud et al. demonstrated in a mouse model that Gram-positive members of Firmicutes like Lactobacillus johnsonii, Lactobacillus murinus, or Enterococcus hirae, were detected in the mesenteric lymph nodes and spleen, which led to a stimulation of TH17 and memory TH1 immune responses, thus possibly enhancing anticancer immune responses [68].

Furthermore, antibiotic-treated ALL patients who suffered an infection within the first 6 months of therapy had a lower phylogenetic diversity in 9 out of 16 cases [39]. Although the infection rate was higher in females, no difference was found between the sexes via Faith's phylogenetic diversity. Comparing microbial composition between ALL patients with and without infection, Faecalibacterium prausnitzii was more abundant in non-infected patients and completely absent in patients with infection and antibiotic treatment [39]. This commensal produces butyrate and reduces proinflammation by blocking the inflammatory cytokine Interleukin-8 [23]. Additionally, Lachnospiraceae and Roseburia, species also known to produce butyrate [69], are reduced in ALL patients [8], which is suggested to increase the risk of mucositis chemotherapy dependently. On the other hand, the abundance of the non-fermenting bacterium Brevudnimonas diminuta, which can be resistant to many different antibiotics, is increased in ALL patients with infectious events [39,70]. In order to investigate factors that cause intestinal mucositis, which can be detected via plasma citrulline levels, stool samples from 51 children were analyzed at different chemotherapy time points [38]. In children with AML, mucositis could be diagnosed using inflammation and cell loss, by measuring Interleukin-8 and plasma citrulline, respectively [71]. Plasma citrulline is produced by enterocytes [38]. Lower levels of citrulline correspond to cell loss and thus to tissue damage and inflammation [72]. Mucositis was also introduced as marker for an increased risk of bacteremia in ALL [72]. Furthermore, plasma C-reactive protein level acts as an indicator for inflammation, and its direct increase at sites of infection was also correlated with the increase in specific bacteria at different therapy time points [38]. Alpha diversity was decreased until day +22 , and was associated with a low plasma citrulline and a high CRP level during mucositis episodes [38]. Interestingly, high citrulline and low levels of CRP were linked to an increased abundance of Lachnospiraceae bacteria, 
which are involved in the biosynthesis of acetate and butyrate. On the other hand, high CRP levels and low citrulline concentrations were associated with an increased abundance of Enterococcus and maximum mucositis severity and inflammation [38]. Low microbial diversity that decreases within the first month is linked to an increase in enterocyte loss and systemic inflammation.

\subsection{Reconstitution after Therapy}

Despite the restoration of normal health after the completion of chemotherapy, several studies have found changes in the microbial gut profile of post-treatment ALL patients to be ongoing [41]. At least 3 months after treatment, the complete bacterial composition of ALL patients remained clearly distinct from healthy controls (Figure 2) [37].

Although no significant differences in alpha diversity could be detected, differences in composition and abundance of some bacteria were still identified [37]. Thomas et al. were able to detect differences between the gut microbiome of ALL survivors (at least 1 year after treatment completion) and that of healthy siblings [42]. Even though no statistically significant differences in alpha or beta diversity could be detected, depletion of members of the Lachnospiraceae and Ruminococcaceae families, including Faecalibacterium, was remarkable [42]. One further study showed that a year after the start of chemotherapy treatment, the gut microbiota had stabilized, but species richness never fully recovered [36]. In particular, abundances of, e.g., Ruminococcus gnavus and Ruminococcus torques were still increased one year after chemotherapy [36]. This suggests that the composition of the gut microbiota is modulated, with some species being substantially altered.

Long-term adult survivors of pediatric ALL who completed therapy at least 5 years before the study by Chua et al. showed reduced microbial diversity compared to healthy controls, with a notable enrichment of Actinobacteria and depletion of Faecalibacterium [41]. Furthermore, in these individuals, increased T-cell activation and chronic inflammation was observed, suggesting a correlation between dysregulated microbial taxa and immune dysregulation [41]. The increased infection risk in survivors [73], a high prevalence of chronic health conditions $[74,75]$ and an elevated risk of mortality and morbidity have been investigated [76]. Thus, microbial dysregulation due to the influences of chemotherapy and antibiotics during ALL treatment may have long-term effects on the development of other diseases, such as obesity or diabetes, in adult survivors of pediatric ALL [41,42].

\section{Outlook: Modulation of the Microbiome}

Due to the described microbiome changes in ALL patients at diagnosis, over the course of chemotherapy and persisting even after several years, modulation of the microbiome is the subject of current research related to its potential protective effects against leukemia development, and its effects on the course of treatment and patient outcome.

Possible strategies to prevent side effects, such as fecal microbiota transplantation (FMT), administration of probiotics or prebiotics, are also under investigation.

FMT is the transfer of fecal substance from a donor to a recipient with the intent to change the recipient's gut microbiota and thus confer a health benefit $[77,78]$. In recent studies, FMT has been used to treat Clostridium difficile (C. difficile) infection, with success rates of up to $85 \%[79,80]$. However, for example in inflammatory bowel diseases FMT did not seem to be as effective as in the treatment of $C$. difficile infection [77]. A possible explanation could be that the pathophyisiology of these diseases is multifactorial [77]. Clinical trials for the treatment of inflammatory bowel diseases in pediatric patients are ongoing [81]. However, no trials focused on hematologic malignancies in children are currently registered. Thus far, there is only data for mouse experiments and case reports for adult patients $[78,82,83]$. In mice, FMT was able to restore the gut microbiome after disruption via antibiotic and chemotherapy administration [83]. In adult patients with blood disorders who harbored antibiotic-resistant bacteria, FMT was performed to eradicate those bacteria, with success rates of $75 \%$ for complete decolonization and $80 \%$ for partial decolonization [82]. However, with this procedure a theoretical risk for infections exists since the 
exact microbial composition of the transplant is not always known [77]. Furthermore, the effects of this procedure in immunocompromised patients need to be further investigated. Standardization of donor screening and selection, as well as sample preparation, route of administration and dosing schedules is needed to be able to systemically examine the effects and risks of this treatment $[77,78,80]$. Due to a lack of data for pediatric ALL patients, optimal approaches for immunosuppressed patients still need to be determined, in order to minimize the risk of infections and procedure-related complications [78]. In particular, the crucial organisms have to be identified and the optimal donors have to be recruited and screened for potential pathogenic microbes in order to guarantee the highest possible level of safety, since the composition of the donor's fecal substance will affect the outcome of the procedure.

Another possibility for modulation of the microbiome is the use of probiotics. Probiotics are defined as "isolated viable organisms administered to confer a health benefit on the host" [78], which can be taken up as part of the diet (e.g., yoghurt, kefir) or in capsules as medication $[84,85]$. For pediatric patients, only a few studies have been published to date investigating the effect of probiotics. In two studies by Reyna-Figueroa et al., postchemotherapy complications like gastro-intestinal side effects were diminished in children with ALL through the use of probiotics, namely Lactobacillus rhamnosus GG [86,87]. However, complications due to infection caused by probiotics have been reported in adult patients [88,89], due to the presence of live organisms that represent a risk for immunocompromised patients. Thus, the use of probiotics must be applied cautiously, with further studies warranted. Precision medicine may be needed, with characterization of the patients gut microbiota, the underlying disease and side effects, in order to guarantee the most effective probiotic treatment.

While FMT and probiotics use live organisms to modulate the microbiome, prebiotics are "substrate[s] that [are] selectively utilized by host microorganisms conferring a health benefit" [90], such as starches or the galacto-oligosaccharides contained in milk [78]. These substances are fermented by microorganisms to produce short-chain fatty acids (SCFAs) like butyrate, which influence immune cell signaling and chemotherapy toxicity and efficacy, among other factors [16,78]. SCFAs have been shown to modulate regulatory T-cell responses in the intestine, resulting in the suppression of pro-inflammatory immune cells $[17,22,78,91,92]$. Thus, supplementing ALL patients with prebiotics may result in a favorable outcome and diminish side effects during therapy. However, further studies are needed to better understand the interactions between diet, expansion of microorganisms and clinical outcomes [78].

\section{Conclusions}

This review gives an overview of microbiome changes in patients with childhood ALL at the time of diagnosis and during treatment, with possible implications for complications, and persisting differences after the completion of therapy. At the onset of disease, reduced diversity in ALL patients is already observed in the oral and gut microbiomes. Further reduction of diversity occurs during treatment, due to the administration of chemotherapeutics and antibiotics. A disturbed microbiome also has implications for side effects during treatment, with dominance of Enteroccocaceae being predictive of infections. Changes to the microbiome, including depletion of Faecalibacterium, can be detected up to several years after completion of treatment, with possible implications for long-term health. However, even with all those studies it remains unclear whether the observed alterations are a causal link for ALL development or due to immunological alterations preceding the emergence of ALL. Monitoring of large pediatric cohorts could be useful to provide direct evidence if the genotype already determines microbial composition, even without the onset of disease.

Taking all of this together, there is a clear need for precise characterization and modulation of patients' microbiomes at each time point during therapy, in order to better understand the microbial influence on leukemogenesis, minimize side effects and improve treatment efficacy. 
Author Contributions: Conceptualization, M.O. and K.L.G.; writing-original draft preparation, N.R. and M.O.; writing — review and editing, A.B., S.J. and K.L.G..; funding acquisition, M.O., K.L.G. and A.B. All authors have read and agreed to the published version of the manuscript.

Funding: This research was funded by German Research Foundation, grant number 428917761 and the Research Committee of the Heinrich Heine University Duesseldorf, grant number 2020-24.

Data Availability Statement: Data sharing not applicable. No new data were created or analyzed in this study. Data sharing is not applicable to this article.

Acknowledgments: We thank Stewart Boden for careful proofreading and editing.

Conflicts of Interest: The authors declare no conflict of interest.

\section{References}

1. Greaves, M. A causal mechanism for childhood acute lymphoblastic leukaemia. Nat. Rev. Cancer 2018, 18, 471-484. [CrossRef]

2. De Luca, F.; Shoenfeld, Y. The microbiome in autoimmune diseases. Clin. Exp. Immunol. 2019, 195, 74-85. [CrossRef]

3. Khan, M.F.; Wang, H. Environmental Exposures and Autoimmune Diseases: Contribution of Gut Microbiome. Front. Immunol. 2019, 10, 3094. [CrossRef] [PubMed]

4. Zheng, D.; Liwinski, T.; Elinav, E. Interaction between microbiota and immunity in health and disease. Cell Res. 2020, 30, 492-506. [CrossRef] [PubMed]

5. Wen, Y.; Jin, R.; Chen, H. Interactions Between Gut Microbiota and Acute Childhood Leukemia. Front. Microbiol. 2019, 10, 1300. [CrossRef] [PubMed]

6. Schwabe, R.F.; Jobin, C. The microbiome and cancer. Nat. Rev. Cancer 2013, 13, 800-812. [CrossRef] [PubMed]

7. Holler, E.; Butzhammer, P.; Schmid, K.; Hundsrucker, C.; Koestler, J.; Peter, K.; Zhu, W.; Sporrer, D.; Hehlgans, T.; Kreutz, M.; et al. Metagenomic analysis of the stool microbiome in patients receiving allogeneic stem cell transplantation: Loss of diversity is associated with use of systemic antibiotics and more pronounced in gastrointestinal graft-versus-host disease. Biol. Blood Marrow Transplant. 2014, 20, 640-645. [CrossRef] [PubMed]

8. Rajagopala, S.V.; Yooseph, S.; Harkins, D.M.; Moncera, K.J.; Zabokrtsky, K.B.; Torralba, M.G.; Tovchigrechko, A.; Highlander, S.K.; Pieper, R.; Sender, L.; et al. Gastrointestinal microbial populations can distinguish pediatric and adolescent Acute Lymphoblastic Leukemia (ALL) at the time of disease diagnosis. BMC Genom. 2016, 17, 635. [CrossRef]

9. Cullen, C.M.; Aneja, K.K.; Beyhan, S.; Cho, C.E.; Woloszynek, S.; Convertino, M.; McCoy, S.J.; Zhang, Y.; Anderson, M.Z.; Alvarez-Ponce, D.; et al. Emerging Priorities for Microbiome Research. Front. Microbiol. 2020, 11, 136. [CrossRef]

10. Vicente-Dueñas, C.; Janssen, S.; Oldenburg, M.; Auer, F.; González-Herrero, I.; Casado-García, A.; Isidro-Hernández, M.; RabosoGallego, J.; Westhoff, P.; Pandyra, A.A.; et al. An intact gut microbiome protects genetically predisposed mice against leukemia. Blood 2020, 136, 2003-2017. [CrossRef]

11. Greaves, M.; Cazzaniga, V.; Ford, A. Can we prevent childhood Leukaemia? Leukemia 2021, 35, 1258-1264. [CrossRef]

12. Nycz, B.T.; Dominguez, S.R.; Friedman, D.; Hilden, J.M.; Ir, D.; Robertson, C.E.; Frank, D.N. Evaluation of bloodstream infections, Clostridium difficile infections, and gut microbiota in pediatric oncology patients. PLoS ONE 2018, 13, e0191232. [CrossRef]

13. Poore, G.D.; Kopylova, E.; Zhu, Q.; Carpenter, C.; Fraraccio, S.; Wandro, S.; Kosciolek, T.; Janssen, S.; Metcalf, J.; Song, S.J.; et al. Microbiome analyses of blood and tissues suggest cancer diagnostic approach. Nature 2020, 579, 567-574. [CrossRef] [PubMed]

14. Neis, E.P.; Dejong, C.H.; Rensen, S.S. The role of microbial amino acid metabolism in host metabolism. Nutrients 2015, 7, 2930-2946. [CrossRef] [PubMed]

15. Hauer, J.; Fischer, U.; Borkhardt, A. Towards prevention of childhood ALL by early-life immune training. Blood 2021. [CrossRef] [PubMed]

16. Coates, M.; Lee, M.J.; Norton, D.; MacLeod, A.S. The Skin and Intestinal Microbiota and Their Specific Innate Immune Systems. Front. Immunol. 2019, 10, 2950. [CrossRef] [PubMed]

17. Tamanai-Shacoori, Z.; Smida, I.; Bousarghin, L.; Loreal, O.; Meuric, V.; Fong, S.B.; Bonnaure-Mallet, M.; Jolivet-Gougeon, A. Roseburia spp.: A marker of health? Future Microbiol. 2017, 12, 157-170. [CrossRef] [PubMed]

18. Švec, P.; Franz, C.M.A.P. The genus Enterococcus. In Lactic Acid Bacteria: Biodiversity and Taxonomy; Holzapfel, W.H., Wood, B.J.B., Eds.; (C) 2021 by John Wiuley \& Sons, Ltd. Registered Office: Chichester, West Sussex, UK, 2014; pp. 175-211.

19. Duncan, S.H.; Louis, P.; Flint, H.J. Lactate-Utilizing Bacteria, Isolated from Human Feces, That Produce Butyrate as a Major Fermentation Product. Appl. Environ. Microbiol. 2004, 70, 5810-5817. [CrossRef] [PubMed]

20. Briliute, J.; Urbanowicz, P.A.; Luis, A.S.; Basle, A.; Paterson, N.; Rebello, O.; Hendel, J.; Ndeh, D.A.; Lowe, E.C.; Martens, E.C.; et al. Complex N-glycan breakdown by gut Bacteroides involves an extensive enzymatic apparatus encoded by multiple co-regulated genetic loci. Nat. Microbiol. 2019, 4, 1571-1581. [CrossRef] [PubMed]

21. Gur, C.; Ibrahim, Y.; Isaacson, B.; Yamin, R.; Abed, J.; Gamliel, M.; Enk, J.; Bar-On, Y.; Stanietsky-Kaynan, N.; Coppenhagen-Glazer, S.; et al. Binding of the Fap2 protein of Fusobacterium nucleatum to human inhibitory receptor TIGIT protects tumors from immune cell attack. Immunity 2015, 42, 344-355. [CrossRef] [PubMed] 
22. Takahashi, K.; Nishida, A.; Fujimoto, T.; Fujii, M.; Shioya, M.; Imaeda, H.; Inatomi, O.; Bamba, S.; Sugimoto, M.; Andoh, A. Reduced Abundance of Butyrate-Producing Bacteria Species in the Fecal Microbial Community in Crohn's Disease. Digestion 2016, 93, 59-65. [CrossRef] [PubMed]

23. Lenoir, M.; Martin, R.; Torres-Maravilla, E.; Chadi, S.; Gonzalez-Davila, P.; Sokol, H.; Langella, P.; Chain, F.; Bermudez-Humaran, L.G. Butyrate mediates anti-inflammatory effects of Faecalibacterium prausnitzii in intestinal epithelial cells through Dact3. Gut Microbes 2020, 12, 1826748. [CrossRef]

24. Tsai, H.F.; Hsu, P.N. Interplay between Helicobacter pylori and immune cells in immune pathogenesis of gastric inflammation and mucosal pathology. Cell Mol. Immunol. 2010, 7, 255-259. [CrossRef] [PubMed]

25. Kittana, H.; Gomes-Neto, J.C.; Heck, K.; Geis, A.L.; Segura Munoz, R.R.; Cody, L.A.; Schmaltz, R.J.; Bindels, L.B.; Sinha, R.; Hostetter, J.M.; et al. Commensal Escherichia coli Strains Can Promote Intestinal Inflammation via Differential Interleukin-6 Production. Front. Immunol. 2018, 9, 2318. [CrossRef] [PubMed]

26. Christofi, T.; Panayidou, S.; Dieronitou, I.; Michael, C.; Apidianakis, Y. Metabolic output defines Escherichia coli as a healthpromoting microbe against intestinal Pseudomonas aeruginosa. Sci. Rep. 2019, 9, 14463. [CrossRef] [PubMed]

27. Van den Elsen, L.W.J.; Garssen, J.; Burcelin, R.; Verhasselt, V. Shaping the Gut Microbiota by Breastfeeding: The Gateway to Allergy Prevention? Front. Pediatr. 2019, 7, 47. [CrossRef] [PubMed]

28. Zhou, Y.J.; Zhao, D.D.; Liu, H.; Chen, H.T.; Li, J.J.; Mu, X.Q.; Liu, Z.; Li, X.; Tang, L.; Zhao, Z.Y.; et al. Cancer killers in the human gut microbiota: Diverse phylogeny and broad spectra. Oncotarget 2017, 8, 49574-49591. [CrossRef] [PubMed]

29. Galloway-Pena, J.R.; Shi, Y.; Peterson, C.B.; Sahasrabhojane, P.; Gopalakrishnan, V.; Brumlow, C.E.; Daver, N.G.; Alfayez, M.; Boddu, P.C.; Khan, M.A.W.; et al. Gut Microbiome Signatures Are Predictive of Infectious Risk Following Induction Therapy for Acute Myeloid Leukemia. Clin. Infect. Dis. 2020, 71, 63-71. [CrossRef]

30. Mancini, N.; Greco, R.; Pasciuta, R.; Barbanti, M.C.; Pini, G.; Morrow, O.B.; Morelli, M.; Vago, L.; Clementi, N.; Giglio, F.; et al. Enteric Microbiome Markers as Early Predictors of Clinical Outcome in Allogeneic Hematopoietic Stem Cell Transplant: Results of a Prospective Study in Adult Patients. Open Forum Infect. Dis. 2017, 4, ofx215. [CrossRef] [PubMed]

31. Wang, Y.; Xue, J.; Zhou, X.; You, M.; Du, Q.; Yang, X.; He, J.; Zou, J.; Cheng, L.; Li, M.; et al. Oral microbiota distinguishes acute lymphoblastic leukemia pediatric hosts from healthy populations. PLoS ONE 2014, 9, e102116. [CrossRef] [PubMed]

32. Bai, L.; Zhou, P.; Li, D.; Ju, X. Changes in the gastrointestinal microbiota of children with acute lymphoblastic leukaemia and its association with antibiotics in the short term. J. Med. Microbiol. 2017, 66, 1297-1307. [CrossRef] [PubMed]

33. Liu, X.; Zou, Y.; Ruan, M.; Chang, L.; Chen, X.; Wang, S.; Yang, W.; Zhang, L.; Guo, Y.; Chen, Y.; et al. Pediatric Acute Lymphoblastic Leukemia Patients Exhibit Distinctive Alterations in the Gut Microbiota. Front. Cell Infect. Microbiol. 2020, 10, 558799. [CrossRef]

34. Huang, Y.; Yang, W.; Liu, H.; Duan, J.; Zhang, Y.; Liu, M.; Li, H.; Hou, Z.; Wu, K.K. Effect of high-dose methotrexate chemotherapy on intestinal Bifidobacteria, Lactobacillus and Escherichia coli in children with acute lymphoblastic leukemia. Exp. Biol. Med. 2012, 237, 305-311. [CrossRef] [PubMed]

35. Hakim, H.; Dallas, R.; Wolf, J.; Tang, L.; Schultz-Cherry, S.; Darling, V.; Johnson, C.; Karlsson, E.A.; Chang, T.C.; Jeha, S.; et al. Gut Microbiome Composition Predicts Infection Risk During Chemotherapy in Children With Acute Lymphoblastic Leukemia. Clin. Infect. Dis. 2018, 67, 541-548. [CrossRef] [PubMed]

36. Rajagopala, S.V.; Singh, H.; Yu, Y.; Zabokrtsky, K.B.; Torralba, M.G.; Moncera, K.J.; Frank, B.; Pieper, R.; Sender, L.; Nelson, K.E. Persistent Gut Microbial Dysbiosis in Children with Acute Lymphoblastic Leukemia (ALL) During Chemotherapy. Microb. Ecol. 2020, 79, 1034-1043. [CrossRef] [PubMed]

37. Chua, L.L.; Rajasuriar, R.; Lim, Y.A.L.; Woo, Y.L.; Loke, P.; Ariffin, H. Temporal changes in gut microbiota profile in children with acute lymphoblastic leukemia prior to commencement-, during-, and post-cessation of chemotherapy. BMC Cancer 2020, 20, 151. [CrossRef]

38. De Pietri, S.; Ingham, A.C.; Frandsen, T.L.; Rathe, M.; Krych, L.; Castro-Mejia, J.L.; Nielsen, D.S.; Nersting, J.; Wehner, P.S.; Schmiegelow, K.; et al. Gastrointestinal toxicity during induction treatment for childhood acute lymphoblastic leukemia: The impact of the gut microbiota. Int. J. Cancer 2020, 147, 1953-1962. [CrossRef]

39. Nearing, J.T.; Connors, J.; Whitehouse, S.; Van Limbergen, J.; Macdonald, T.; Kulkarni, K.; Langille, M.G.I. Infectious Complications Are Associated With Alterations in the Gut Microbiome in Pediatric Patients With Acute Lymphoblastic Leukemia. Front. Cell Infect. Microbiol. 2019, 9, 28. [CrossRef] [PubMed]

40. Wang, Y.; Zeng, X.; Yang, X.; Que, J.; Du, Q.; Zhang, Q.; Zou, J. Oral Health, Caries Risk Profiles, and Oral Microbiome of Pediatric Patients with Leukemia Submitted to Chemotherapy. BioMed Res. Int. 2021, 2021, 6637503. [CrossRef] [PubMed]

41. Chua, L.L.; Rajasuriar, R.; Azanan, M.S.; Abdullah, N.K.; Tang, M.S.; Lee, S.C.; Woo, Y.L.; Lim, Y.A.; Ariffin, H.; Loke, P. Reduced microbial diversity in adult survivors of childhood acute lymphoblastic leukemia and microbial associations with increased immune activation. Microbiome 2017, 5, 35. [CrossRef]

42. Thomas, R.; Wong, W.S.W.; Saadon, R.; Vilboux, T.; Deeken, J.; Niederhuber, J.; Hourigan, S.K.; Yang, E. Gut microbial composition difference between pediatric ALL survivors and siblings. Pediatr. Hematol. Oncol. 2020, 37, 475-488. [CrossRef] [PubMed]

43. Johnson, J.S.; Spakowicz, D.J.; Hong, B.Y.; Petersen, L.M.; Demkowicz, P.; Chen, L.; Leopold, S.R.; Hanson, B.M.; Agresta, H.O.; Gerstein, M.; et al. Evaluation of $16 \mathrm{~S}$ rRNA gene sequencing for species and strain-level microbiome analysis. Nat. Commun. 2019, 10, 5029. [CrossRef] [PubMed] 
44. Lim, H.C.; Kim, C.S. Oral signs of acute leukemia for early detection. J. Periodontal. Implant. Sci. 2014, 44, 293-299. [CrossRef] [PubMed]

45. Lauritano, D.; Petruzzi, M.; Fumagalli, T.; Giacomello, M.S.; Caccianiga, G. Oral Manifestations in Children with Acute Lymphoblastic Leukemia. Eur. J. Inflamm. 2012, 10, 65-68. [CrossRef]

46. Vacca, M.; Celano, G.; Calabrese, F.M.; Portincasa, P.; Gobbetti, M.; De Angelis, M. The Controversial Role of Human Gut Lachnospiraceae. Microorganisms 2020, 8, 573. [CrossRef]

47. Inaba, H.; Pei, D.; Wolf, J.; Howard, S.C.; Hayden, R.T.; Go, M.; Varechtchouk, O.; Hahn, T.; Buaboonnam, J.; Metzger, M.L.; et al. Infection-related complications during treatment for childhood acute lymphoblastic leukemia. Ann. Oncol. 2017, $28,386-392$. [CrossRef] [PubMed]

48. Tidjani Alou, M.; Lagier, J.-C.; Raoult, D. Diet influence on the gut microbiota and dysbiosis related to nutritional disorders. Hum. Microbiome J. 2016, 1, 3-11. [CrossRef]

49. Milani, C.; Duranti, S.; Bottacini, F.; Casey, E.; Turroni, F.; Mahony, J.; Belzer, C.; Delgado Palacio, S.; Arboleya Montes, S.; Mancabelli, L.; et al. The First Microbial Colonizers of the Human Gut: Composition, Activities, and Health Implications of the Infant Gut Microbiota. Microbiol. Mol. Biol. Rev. 2017, 81, 20121173. [CrossRef]

50. Henrick, B.M.; Chew, S.; Casaburi, G.; Brown, H.K.; Frese, S.A.; Zhou, Y.; Underwood, M.A.; Smilowitz, J.T. Colonization by B. infantis EVC001 modulates enteric inflammation in exclusively breastfed infants. Pediatr. Res. 2019, 86, 749-757. [CrossRef]

51. Fattizzo, B.; Cavallaro, F.; Folino, F.; Barcellini, W. Recent insights into the role of the microbiome in malignant and benign hematologic diseases. Crit. Rev. Oncol. Hematol. 2021, 160, 103289. [CrossRef]

52. Blijlevens, N.M.; Donnelly, J.P.; De Pauw, B.E. Mucosal barrier injury: Biology, pathology, clinical counterparts and consequences of intensive treatment for haematological malignancy: An overview. Bone Marrow Transplant. 2000, 25, 1269-1278. [CrossRef] [PubMed]

53. Zhang, X.; Shi, L.; Sun, T.; Guo, K.; Geng, S. Dysbiosis of gut microbiota and its correlation with dysregulation of cytokines in psoriasis patients. BMC Microbiol. 2021, 21, 78. [CrossRef] [PubMed]

54. De Ryck, T.; Vanlancker, E.; Grootaert, C.; Roman, B.I.; De Coen, L.M.; Vandenberghe, I.; Stevens, C.V.; Bracke, M.; Van de Wiele, T.; Vanhoecke, B. Microbial inhibition of oral epithelial wound recovery: Potential role for quorum sensing molecules? $A M B$ Express 2015, 5, 27. [CrossRef] [PubMed]

55. Fijlstra, M.; Ferdous, M.; Koning, A.M.; Rings, E.H.H.M.; Harmsen, H.J.M.; Tissing, W.J.E. Substantial decreases in the number and diversity of microbiota during chemotherapy-induced gastrointestinal mucositis in a rat model. Support. Care Cancer 2014, 23, 1513-1522. [CrossRef]

56. Kwong, Y.L.; Yeung, D.Y.; Chan, J.C. Intrathecal chemotherapy for hematologic malignancies: Drugs and toxicities. Ann. Hematol. 2009, 88, 193-201. [CrossRef] [PubMed]

57. Zhou, B.; Xia, X.; Wang, P.; Chen, S.; Yu, C.; Huang, R.; Zhang, R.; Wang, Y.; Lu, L.; Yuan, F.; et al. Induction and Amelioration of Methotrexate-Induced Gastrointestinal Toxicity are Related to Immune Response and Gut Microbiota. EBioMedicine 2018, 33, 122-133. [CrossRef] [PubMed]

58. Ding, Y.H.; Qian, L.Y.; Pang, J.; Lin, J.Y.; Xu, Q.; Wang, L.H.; Huang, D.S.; Zou, H. The regulation of immune cells by Lactobacilli: A potential therapeutic target for anti-atherosclerosis therapy. Oncotarget 2017, 8, 59915-59928. [CrossRef] [PubMed]

59. Ruiz, L.; Delgado, S.; Ruas-Madiedo, P.; Sanchez, B.; Margolles, A. Bifidobacteria and Their Molecular Communication with the Immune System. Front. Microbiol. 2017, 8, 2345. [CrossRef] [PubMed]

60. Franzin, M.; Stefancic, K.; Lucafo, M.; Decorti, G.; Stocco, G. Microbiota and Drug Response in Inflammatory Bowel Disease. Pathogens 2021, 10, 211. [CrossRef]

61. Zimmermann, M.; Zimmermann-Kogadeeva, M.; Wegmann, R.; Goodman, A.L. Mapping human microbiome drug metabolism by gut bacteria and their genes. Nature 2019, 570, 462-467. [CrossRef]

62. Fakhoury, M.; de Beaumais, T.; Medard, Y.; Jacqz-Aigrain, E.; Suivi Thérapeutique Pharmacologique de la Société Française de Pharmacologie et de Thérapeutique. Therapeutic drug monitoring of 6-thioguanine nucleotides in paediatric acute lymphoblastic leukaemia: Interest and limits. Therapie 2010, 65, 187-193. [CrossRef] [PubMed]

63. Liu, F.; Ma, R.; Riordan, S.M.; Grimm, M.C.; Liu, L.; Wang, Y.; Zhang, L. Azathioprine, Mercaptopurine, and 5-Aminosalicylic Acid Affect the Growth of IBD-Associated Campylobacter Species and Other Enteric Microbes. Front. Microbiol. 2017, 8, 527. [CrossRef]

64. Rigby, R.J.; Carr, J.; Orgel, K.; King, S.L.; Lund, P.K.; Dekaney, C.M. Intestinal bacteria are necessary for doxorubicin-induced intestinal damage but not for doxorubicin-induced apoptosis. Gut Microbes 2016, 7, 414-423. [CrossRef] [PubMed]

65. Yan, A.; Culp, E.; Perry, J.; Lau, J.T.; MacNeil, L.T.; Surette, M.G.; Wright, G.D. Transformation of the Anticancer Drug Doxorubicin in the Human Gut Microbiome. ACS Infect. Dis. 2018, 4, 68-76. [CrossRef] [PubMed]

66. Dutta, D.; Lim, S.H. Bidirectional interaction between intestinal microbiome and cancer: Opportunities for therapeutic interventions. Biomark. Res. 2020, 8, 31. [CrossRef]

67. Yang, J.; Liu, K.X.; Qu, J.M.; Wang, X.D. The changes induced by cyclophosphamide in intestinal barrier and microflora in mice. Eur. J. Pharmacol. 2013, 714, 120-124. [CrossRef] [PubMed]

68. Viaud, S.; Saccheri, F.; Mignot, G.; Yamazaki, T.; Daillère, R.; Hannani, D.; Enot, D.P.; Pfirschke, C.; Engblom, C.; Pittet, M.J.; et al. The Intestinal Microbiota Modulates the Anticancer Immune Effects of Cyclophosphamide. Science 2013, 342, 971-976. [CrossRef] [PubMed] 
69. Vital, M.; Karch, A.; Pieper, D.H. Colonic Butyrate-Producing Communities in Humans: An Overview Using Omics Data. mSystems 2017, 2, e00130-17. [CrossRef]

70. Ryan, M.P.; Pembroke, J.T. Brevundimonas spp.: Emerging global opportunistic pathogens. Virulence 2018, 9, 480-493. [CrossRef] [PubMed]

71. Van Vliet, M.J.; Tissing, W.J.; Rings, E.H.; Koetse, H.A.; Stellaard, F.; Kamps, W.A.; de Bont, E.S. Citrulline as a marker for chemotherapy induced mucosal barrier injury in pediatric patients. Pediatr. Blood Cancer 2009, 53, 1188-1194. [CrossRef]

72. De Pietri, S.; Frandsen, T.L.; Christensen, M.; Grell, K.; Rathe, M.; Muller, K. Citrulline as a biomarker of bacteraemia during induction treatment for childhood acute lymphoblastic leukaemia. Pediatr. Blood Cancer 2021, 68, e28793. [CrossRef] [PubMed]

73. Pelland-Marcotte, M.-C.; Pole, J.D.; Hwee, J.; Sutradhar, R.; Science, M.; Nathan, P.C.; Sung, L. Long-Term Risk of Infections After Treatment of Childhood Leukemia: A Population-Based Cohort Study Using Administrative Health Data. J. Clin. Oncol. 2019, 37, 2651-2660. [CrossRef] [PubMed]

74. Oeffinger, K.C.; Mertens, A.C.; Sklar, C.A.; Kawashima, T.; Hudson, M.M.; Meadows, A.T.; Friedman, D.L.; Marina, N.; Hobbie, W.; Kadan-Lottick, N.S.; et al. Chronic Health Conditions in Adult Survivors of Childhood Cancer. N. Engl. J. Med. 2006, 355, 1572-1582. [CrossRef] [PubMed]

75. Hudson, M.M.; Ness, K.K.; Gurney, J.G.; Mulrooney, D.A.; Chemaitilly, W.; Krull, K.R.; Green, D.M.; Armstrong, G.T.; Nottage, K.A.; Jones, K.E.; et al. Clinical Ascertainment of Health Outcomes Among Adults Treated for Childhood Cancer. JAMA 2013, 309, 2371-2381. [CrossRef]

76. Armstrong, G.T.; Kawashima, T.; Leisenring, W.; Stratton, K.; Stovall, M.; Hudson, M.M.; Sklar, C.A.; Robison, L.L.; Oeffinger, K.C. Aging and risk of severe, disabling, life-threatening, and fatal events in the childhood cancer survivor study. J. Clin. Oncol. 2014, 32, 1218-1227. [CrossRef]

77. Gupta, S.; Allen-Vercoe, E.; Petrof, E.O. Fecal microbiota transplantation: In perspective. Ther. Adv. Gastroenterol. 2016, 9, 229-239. [CrossRef] [PubMed]

78. Severyn, C.J.; Brewster, R.; Andermann, T.M. Microbiota modification in hematology: Still at the bench or ready for the bedside? Blood Adv. 2019, 3, 3461-3472. [CrossRef] [PubMed]

79. Drekonja, D.; Reich, J.; Gezahegn, S.; Greer, N.; Shaukat, A.; MacDonald, R.; Rutks, I.; Wilt, T.J. Fecal Microbiota Transplantation for Clostridium difficile Infection: A Systematic Review. Ann. Intern. Med. 2015, 162, 630-638. [CrossRef]

80. Kim, P.; Gadani, A.; Abdul-Baki, H.; Mitre, R.; Mitre, M. Fecal microbiota transplantation in recurrent Clostridium difficile infection: A retrospective single-center chart review. JGH Open 2019, 3, 4-9. [CrossRef]

81. FMT Trials. Available online: https://clinicaltrials.gov/ct2/results?cond=fecal+microbiota+transplant\&Search=Apply\&age_v= \&age $=0$ \&gnd $r=\&$ type $=\& r s 1 t=($ accessed on 1 July 2021).

82. Bilinski, J.; Grzesiowski, P.; Sorensen, N.; Madry, K.; Muszynski, J.; Robak, K.; Wroblewska, M.; Dzieciatkowski, T.; Dulny, G.; Dwilewicz-Trojaczek, J.; et al. Fecal Microbiota Transplantation in Patients With Blood Disorders Inhibits Gut Colonization With Antibiotic-Resistant Bacteria: Results of a Prospective, Single-Center Study. Clin. Infect. Dis. 2017, 65, 364-370. [CrossRef] [PubMed]

83. Le Bastard, Q.; Ward, T.; Sidiropoulos, D.; Hillmann, B.M.; Chun, C.L.; Sadowsky, M.J.; Knights, D.; Montassier, E. Fecal microbiota transplantation reverses antibiotic and chemotherapy-induced gut dysbiosis in mice. Sci. Rep. 2018, 8, 6219. [CrossRef]

84. Rotz, S.J.; Dandoy, C.E. The microbiome in pediatric oncology. Cancer 2020, 126, 3629-3637. [CrossRef]

85. Sharifi, M.; Moridnia, A.; Mortazavi, D.; Salehi, M.; Bagheri, M.; Sheikhi, A. Kefir: A powerful probiotics with anticancer properties. Med. Oncol. 2017, 34, 183. [CrossRef]

86. Reyna-Figueroa, J.; Barrón-Calvillo, E.; García-Parra, C.; Galindo-Delgado, P.; Contreras-Ochoa, C.; Lagunas-Martínez, A.; Campos-Romero, F.H.; Silva-Estrada, J.A.; Limón-Rojas, A.E. Probiotic Supplementation Decreases Chemotherapy-induced Gastrointestinal Side Effects in Patients With Acute Leukemia. J. Pediatr. Hematol. Oncol. 2019, 41, 468-472. [CrossRef] [PubMed]

87. Reyna-Figueroa, J.; Bejarano-Juvera, A.A.; García-Parra, C.; Barrón-Calvillo, E.E.; Queipo-Garcia, G.E.; Galindo-Delgado, P. Decrease of Postchemotherapy Complications With the Use of Probiotics in Children With Acute Lymphoblastic Leukemia. J. Pediatr. Hematol. Oncol. 2021, 43, e457-e461. [CrossRef] [PubMed]

88. Sherid, M.; Samo, S.; Sulaiman, S.; Husein, H.; Sifuentes, H.; Sridhar, S. Liver abscess and bacteremia caused by lactobacillus: Role of probiotics? Case report and review of the literature. BMC Gastroenterol. 2016, 16, 138. [CrossRef] [PubMed]

89. Koyama, S.; Fujita, H.; Shimosato, T.; Kamijo, A.; Ishiyama, Y.; Yamamoto, E.; Ishii, Y.; Hattori, Y.; Hagihara, M.; Yamazaki, E.; et al. Septicemia from Lactobacillus rhamnosus GG, from a Probiotic Enriched Yogurt, in a Patient with Autologous Stem Cell Transplantation. Probiotics AntiMicrob. Proteins 2019, 11, 295-298. [CrossRef]

90. Gibson, G.R.; Hutkins, R.; Sanders, M.E.; Prescott, S.L.; Reimer, R.A.; Salminen, S.J.; Scott, K.; Stanton, C.; Swanson, K.S.; Cani, P.D.; et al. Expert consensus document: The International Scientific Association for Probiotics and Prebiotics (ISAPP) consensus statement on the definition and scope of prebiotics. Nat. Rev. Gastroenterol. Hepatol. 2017, 14, 491-502. [CrossRef] [PubMed]

91. Smith, P.M.; Howitt, M.R.; Panikov, N.; Michaud, M.; Gallini, C.A.; Bohlooly-Y, M.; Glickman, J.N.; Garrett, W.S. The Microbial Metabolites, Short-Chain Fatty Acids, Regulate Colonic $\mathrm{T}_{\text {reg }}$ Cell Homeostasis. Science 2013, 341, 569-573. [CrossRef]

92. Zhang, S.L.; Wang, S.N.; Miao, C.Y. Influence of Microbiota on Intestinal Immune System in Ulcerative Colitis and Its Intervention. Front. Immunol. 2017, 8, 1674. [CrossRef] [PubMed] 